Western University

Scholarship@Western

2020

\title{
Understanding Global Change: From Documentation and Collaboration to Social Transformation
}

Karen E. Pennesi

University of Western Ontario, pennesi@uwo.ca

Follow this and additional works at: https://ir.lib.uwo.ca/anthropub

Part of the African Studies Commons, Asian Studies Commons, Biodiversity Commons, Environmental Studies Commons, Human Geography Commons, Latin American Studies Commons, Nature and Society Relations Commons, and the Social and Cultural Anthropology Commons

\section{Citation of this paper:}

Pennesi, Karen (2020) “Understanding Global Change: From Documentation and Collaboration to Social Transformation." In Changing Climate, Changing Worlds: Local Knowledge and the Challenges of Social and Ecological Change. Meredith Welch-Devine, Anne Sourdril and Brian Burke (eds.). Switzerland: Springer Nature. Pp. 243-258. 


\title{
Understanding Global Change: From Documentation and Collaboration to Social Transformation
}

\author{
Karen Pennesi \\ University of Western Ontario \\ pennesi@uwo.ca
}

Citation:

Pennesi, Karen (2020) "Understanding Global Change: From Documentation and Collaboration to Social Transformation." In Changing Climate, Changing Worlds: Local Knowledge and the Challenges of Social and Ecological Change. Meredith Welch-Devine, Anne Sourdril and Brian Burke (eds.). Switzerland: Springer Nature. Pp. 243-258.

\section{Abstract}

The conclusion to the book situates the chapters within four programs of anthropological research on climate change: (1) documentation of local impacts of and adaptations to climate change, (2) connections to socioeconomic and political contexts, (3) collaborations with nonanthropologists, and (4) activism and social transformation. The final section notes the persistent challenges to creating positive change and meaningful research outcomes. It highlights some examples of success and outlines future directions for politically engaged anthropological work around climate change.

Keywords Climate change - Collaborative research - Environmental anthropology . Democratization · Decolonizing research 


\subsection{Decolonizing Environmental Knowledge and Climate Change Research}

Anyone who has spent time among people who make their living off the land-farmers, fishers, animal producers - can attest to their resourcefulness, their resilience in the face of hazards and changes, and their detailed knowledge of the natural environment in which they live and work. Some would argue that it is a matter of survival to be so attentive, creative and cooperative. Others might point to the collective wisdom passed down over generations of trial, error and innovation. In my own work with smallholder farmers in Northeast Brazil, I have listened to stories proudly told about persistence despite economic hardship, endurance through suffering in times of drought, and hard-won success after trying some new technique or crop. I was a witness to their labour and I saw clearly the connections between moral worth and willingness to undertake difficult work (Pennesi 2015). What I also observed repeatedly was a deep sense of frustration among peasant farmers, sometimes bordering on resignation, with the political and economic systems that constrained their pursuits and disadvantaged them in relation to large-scale agribusiness, city-dwellers or others with more money and influence. Over ten years of doing research in the state of Ceará, I heard from many people that agropastoralism could be more successful there, even at the subsistence level, if there were better management of water resources and government policies to support infrastructure and social development appropriate to the semi-arid climate. "Conviver com o semi-árido" ('living with the semi-arid') is a phrase often used to describe policies and programs that are progressive in building capacity for sustainable production in rural areas of the Brazilian Northeast. In reviewing related literature-including the preceding chapters of this book-I have learned that the problem I see in Ceará is one familiar to those who work with peasant farmers or subsistence fishers in other parts of the world. Political, economic and social structures limit the adaptive capacity of individuals and communities, increasing vulnerability to natural hazards such as droughts and floods. The obvious conclusion is that if natural disasters are a product of both environmental conditions and social factors (Blaikie et al. 1994), then mitigation or prevention of disasters must include social change (Ribot et al. 1996).

The question I originally set out to investigate in Ceará was why farmers were not using meteorological forecasts disseminated by the state-funded agency in their agricultural decisionmaking. I soon discovered that there was a competing source of predictions for the rainy season: people known as profetas da chuva, 'rain prophets', who based their forecasts on empirical observations of plants, animals, birds, celestial bodies and other indicators in their environment (Pennesi 2011). This local environmental knowledge was valued by the farmers who lived alongside the rain prophets but was more often dismissed by scientists and urban consumers of news reports as being merely folklore or superstition. At the same time, the government meteorological agency offering the official climate forecast was not trusted by farmers, who criticized the meteorologists' lack of local place-based knowledge as well as the agency's connection to the state, which they saw as both interfering and wilfully negligent 
(Pennesi 2013). Each year, a deeply rooted and complex conflict between rural and urban, tradition and science, citizen and state played out in discussions of the rainy season. The rain prophets represented a symbolic resistance to the dominance and arrogance of decontextualized scientific knowledge (Taddei 2012), and to the federal and state governments whose claims to be helping disguised structures that marginalized farmers. Over the last two decades, there has been a shift in public discourse toward acknowledging the wisdom and experience of local and traditional knowledge embodied by rain prophets (Taddei 2006). Efforts are being made at the regional level to valorize and document the work of rain prophets in annual public meetings, media reports, academic publications, documentary films and theatrical productions, and to encourage young people to carry on the traditional practices (Pennesi and Souza 2012). As Taddei (2012) argues, however, the positive attention toward rain prophets as cultural performers has not resulted in any kind of organized political movement that could make significant differences in the farmers' lives. The authority and legitimacy of scientific knowledge remain unquestioned at the level of state policy, while the rural population remains largely poor and dependent on governmental and non-governmental programs for any measurable improvement in their situation.

This background brings me to the frameworks of decolonization and democratization that I use to organize this concluding chapter. I start with a quote by Chandra Talpade Mohanty (2003:254) which links the two: "Decolonization involves both engagement with the everyday issues in our own lives so that we can make sense of the world in relation to hegemonic power, and engagement with collectivities that are premised on ideas of autonomy and selfdetermination, in other words, democratic practice." Decolonization and democratization emerge in response to colonial and authoritarian governance structures whose purpose is to amass land, resources and power, and which necessarily create subordinate populations. The goal of these movements is for Indigenous and subjugated peoples to have ownership and control over management of natural resources, over their livelihoods, over their way of life, and over their knowledge and thoughts. In short, they are a response to the fast and slow violences that Burke, Welch-Devine, and Sourdril discuss in the introduction to this book. With democratization, there is a focus on equality and participation in decision-making in all domains of social life. In this book, these issues apply to adaptations and responses to environmental and climatic conditions. Decolonization involves movement toward independence in all spheres of activity, including research (Smith 2012). In this chapter, I am interested in how giving attention and credibility to Indigenous/traditional/empirical knowledge decenters colonial and hegemonic epistemologies.

In their article entitled, "Decolonization is not a metaphor," Eve Tuck and K. Wayne Yang (2012) insist that "decolonization specifically requires the repatriation of Indigenous land and life" (p. 21) and caution against using "decolonizing" to describe struggles against all forms of systemic social injustice (p. 17). The communities discussed in this book are not all Indigenous peoples living in the settler colonial states that Tuck and Yang write about, but what is relevant here is their focus on the material aspects of decolonization and the vital importance of land. 
The colonial/capitalist transformation of land into property and resource, and the concentration of land as wealth in the hands of powerful minorities, underlies the vulnerability of many communities described here. Furthermore, the exploitation of land-based resources, such as fossil fuels, in the pursuit of wealth and power is widely understood to be a primary cause of global climate change (IPCC 2013). As the research in this volume demonstrates, those who derive their subsistence directly from the land and water tend to be among the internally marginalized groups who suffer social discrimination, leaving them particularly vulnerable to natural hazards and climate variations. Therefore, analyses of perceptions of and adaptations to global changes, including climate change, must be understood within the context of struggles for self-determination and fuller participation in political and economic life.

An anthropological approach is especially well suited to illuminating the interconnections among multiple dynamic systems and forces, and tracing how different human groups act within these systems over time. With people at the centre, anthropologists investigate ecosystems, atmospheric conditions, social structures, and cultural systems of meaning-making, in addition to physiological processes and characteristics. The international group of scholars contributing to this book elucidates both human and environmental perspectives on the topic of climate change, drawing on cultural and biological anthropology as well as botany (Salick et al.) and geography (Dervieux and Belgherbi). A wide range of qualitative and quantitative methods are employed in these ethnographic studies, including interviews (Katz et al.; Dervieux and Belgherbi; Roque de Pinho; Sourdril et al.; Galvin et al.; Salick et al.; Burke et al.), surveys and questionnaires (Katz et al.; Seara et al.), participant observation (Dervieux and Belgherbi; Sourdril et al.), group discussions (Katz et al.; Roque de Pinho; Galvin et al.), community workshops (Galvin et al.), creation of a an interactive web site (Reyes-García et al.), free listing observations of local flora and fauna (Dervieux and Belgherbi; Burke et al.), pile sorts, calendar construction and mapping (Salick et al.), participatory photography and video-making (Galvin et al.; Roque de Pinho; Salick et al.), accompanied field visits (Salick et al.), statistical analysis (Salick et al.; Seara et al), and path analysis (Seara et al.). Such a variety of methods enables the rich and nuanced analyses that are characteristic of anthropology and is evidence of an evolving understanding of what it means to study people.

This chapter is organized around four programmatic categories of anthropological research on human responses to climatic and environmental changes. The first category stems from the foundational interest of anthropology in the relationship between people and their environment. It centers on documentation of various adaptive strategies in particular climates (e.g. Moran 2008) and more recently includes descriptions of "local observations in climate sensitive places" (Crate and Nuttall 2016:13; Reuter 2015). The second kind of anthropological research on climate change moves beyond documentation of local observations and perceptions to examine the broader socioeconomic and political contexts that shape experiences of changing environments (Casagrande et al. 2007; Pokrant and Stocker 2011). The third category of research is marked by collaboration with interdisciplinary teams and with local people as research partners (Ayers and Forsyth 2009; Crate and Nuttall 2009). Collaboration 
and participatory methodologies demonstrate that local and Indigenous knowledge is valued and this kind of research supports the capacity of local people to contribute to their own understanding. The fourth category of anthropological research related to climate change aims to foster social transformation by working alongside local community members in service of their own goals and projects. In these research programs, scholars take a more activist stance in their work to influence policy and facilitate social change (e.g. Baer and Singer 2018; Crate and Nuttall 2016). In the remainder of this concluding chapter, I show how the previous chapters relate to each of these four categories of research. Recognizing that it is impossible to make meaningful generalizations across such diverse geographical, cultural and social contexts as are represented in the preceding chapters, I nonetheless attempt to identify common threads, while highlighting particular cases when relevant. The chapter finishes with a brief discussion of remaining challenges and argues for future anthropological work to further the goal of social transformation through decolonization and democratization. I argue for a politically engaged anthropology of climate change befitting the seriousness, urgency and global reach of the topic.

\subsection{Anthropology and Climate Change}

\subsubsection{Documentation}

Anthropology has long held that adaptation to climate and environment is a fundamental human capacity. Numerous theories have been proposed over the last century to explain variation in human physiology, livelihoods, cultures and political systems in relation to environmental conditions (Dove and Carpenter 2008). This earlier work teaches us that the effects of climate change must be understood from a human ecological perspective which considers how land use for settlement, agriculture and other purposes influences the ecosystem, and at the same time, human activities are shaped by shifting environmental conditions (e.g. chapters in this volume by Burke et al.; Katz et al.; Galvin et al.; Sourdril et al.). Anthropology offers unique insights to our collective knowledge of ongoing global changes and adaptations to them. Ethnographic fieldwork, attention to the historical context of contemporary climate debates, and an integrated view of human and natural systems are important aspects of anthropological research that can inform understandings of climate change (Barnes et al. 2013). Each of the preceding chapters has demonstrated these characteristics in its presentation of research examining local perceptions of how changing conditions affect relationships between plants, animals, humans, water and land, in Africa (Zimbabwe, Kenya, Cameroon), Asia (Eastern Himalayan region), Europe (France, Spain), North America (Puerto Rico, Southern Appalachia), and South America (Brazil).

Providing portraits of what changing weather patterns and environments look like in different parts of the world, the authors of the preceding chapters contribute to a wellestablished anthropological literature (Barnes and Dove 2015; Crate and Nuttall 2009; Dove 2014; Jankovic and Barboza 2009; Lazrus 2012; Strauss and Orlove 2003). We learn that at the local level, climate change is felt and understood in ways very different from what is described in reports focusing on global-scale meteorological and geographic trends, such as rising 
temperatures, melting icecaps, rising sea levels and increased carbon dioxide in the air. In documenting these experiences, this book deepens our understanding of the kinds of changes that are occurring and adds a human dimension to geographic and atmospheric descriptions. Importantly, the publication of these findings gives a voice to people who are often marginalized within their own societies. Below is a list of the impacts of climate change research participants have observed:

- Increase/decrease in rainfall/snowfall and more extreme events

- Changes to onset and duration of seasons

- Increase in seasonal temperatures

- Retreat of glaciers

- Changes in flora and fauna that make prediction of climatic phenomena difficult

- Difficulties in growing particular crops; less reliable harvests

- Vegetation in high altitudes dominated by warmer temperature species

- Proliferation of weeds

- Shifting of treelines further up the mountains

- Increased incidence of diseased vegetation and insect attacks

- Changes in water quality, affecting life cycles and distribution of fish important to humans

- Loss of habitat for fish

- Wild animals searching for food in human settlements or dying of starvation

These observations are made with both bodies and minds, and the effects are felt in profound emotional and psychological ways-not just physical ways that can be counted and measured. Throughout the chapters, it is clear that these changes matter. They are significant to individuals as well as to communities and cultural groups, who are struggling to make a living and to live well according to their own cultural traditions and personal convictions.

This book presents insightful studies of the consequences of different adaptive responses for particular populations. For example, the chapters by Seara et al. and Salick et al. describe how adaptations to negative impacts of climate change present new risks, such as those pursuing livelihood activities that are more dangerous, less sustainable, or less profitable. Salick, Staver and Hart observe that planting traditional crops and taking animals to graze higher up in the Himalaya mountains involves riskier travel, while moving to new livelihood activities such as agroforestry, tourism and growing cash crops brings other problems. Meanwhile, Seara, Pollnac and Jakubowski highlight the intersectionality of risk types where environmental changes and climate change exacerbate the socio-economic vulnerability of fishers in Puerto Rico. They take into account the sociocultural and psychological factors that influence decisions and feelings, noting that some fishers are reluctant to give up fishing altogether to pursue other livelihoods, despite the risks and problems associated with it, because fishing is part of their identity and their social relationships. Depending on their age, education, level of experience and satisfaction with fishing, some fishers adapt to reduced 
numbers of the usual fish in the usual places by pursuing new livelihoods, while others take risks finding new fishing grounds in deeper waters, and still others accept the dangers of SCUBA diving. These examples help us understand how sociocultural factors beyond rational decisionmaking shape adaptation in important ways. Studies such as these are essential if we aim to develop adaptation practices, programs and policies that are effective and culturally appropriate.

\subsubsection{Connections}

The chapters in the current volume showcase the breadth of anthropological research on the complexities of climate change problems and solutions, which intertwine environment, culture, sociopolitical processes, local and global economic systems, and individual human experience. They demonstrate that climate change is not just about the environment, but about how the environment is implicated in human relationships and how people see themselves in the world.

Deverieux and Belgherbi reveal interconnections between climate change, environmental practices, religious beliefs and politics. They describe discourses circulating among residents of communal lands near a protected area in Zimbabwe, in which angry ancestors cause droughts, deforestation, soil erosion, reduction of plant and animal species, and negative interactions with elephants, lions and other animals. Research participants explain that the ancestors are angry because people no longer do ritual rainmaking ceremonies and violate taboos on using some plant and animal species. These transgressions occur because the villagers no longer have access to ancestral sites within the protected lands, the population has grown, and the spread of Christianity has discouraged traditional spiritual practices. The authors argue that the discourse in which climate change and its environmental effects are attributed to angry ancestors is effectively a political commentary on the marginalization of these rural people from their traditional lands as well as their exclusion from a national community-based natural management program. Here, we see how climate change is linked explicitly with appeals for democratization. Similarly, Salick, Staver and Hart reported that many Tibetans believe climate change is caused by bad deeds and that good deeds will appease angry gods and restore balance. Compounding the material disadvantages that follow from disconnecting people from the land, we see how "the disruption of Indigenous relationships to land represents a profound epistemic, ontological, cosmological violence" (Tuck and Yang 2012:5). These studies indicate that relationships between people and the rest of the natural world are understood to be inherently moral and political.

Two additional examples highlight the political dimension of human interactions with their environments. Sourdril and colleagues explain that the proliferation of wild flora in the rural area of Bas-Comminges, France results both from a warmer, wetter climate and from changes in public infrastructure. In the past, government workers used herbicides to remove weeds in public green spaces. Nowadays, the management of the green spaces is left to community groups and herbicides are restricted. Conflict arises because newcomers favor manual weed removal, while most locally-born residents prefer to use herbicides. Furthermore, 
there is disagreement about which plants should be removed and which should be left for aesthetic reasons or harvested for various uses. In this way, "the weeds issue reveals not only the impacts of seasonal variations and climate changes but also profound changes in the organization of the institutions, local societies and the French rural world" (Chap. 5).

Finally, Burke, Welch-Devine, Steacy and Rzonca suggest that collective response to climate change in the Southern Appalachia region of the U.S. may be impeded by a general and long-standing lack of trust in science and government. Their work urges us to attend not only to local environmental knowledge, but to local attitudes and beliefs about how government and society function. Thus, this book's examination of human responses to climate change leads us to insights about human relationships and social structures.

\subsubsection{Collaborations}

Several contributors to this book have found ways to "move beyond descriptions of social and cultural effects of climate change" (Crate and Nuttall 2016:7), by collaborating with participants to produce outputs that can be used by other academic and lay researchers. Making new data and ways of knowing available to researchers worldwide enables comparisons and the recognition of trends and patterns. For instance, the interactive web-based platform (CONECTe) created by Reyes-García, Fernández-Llamazares, García-del-Amo and Cabeza, along with the citizen scientists who shared their local and Indigenous knowledge of climate change impacts, demonstrates how anthropological research collaborations can bridge local and global aspects of climate change. While acknowledging challenges arising from the incommensurability of some kinds of environmental knowledge and the continual need for widespread participation, this project delineates a path forward for research that combines local and scientific knowledge, and that potentially involves people of all ages. Engaging 'citizen scientists' increases relevance and promotes education and awareness of climate change. The project also has the potential to provide data for comparative analyses of changes over time and across space. Expanding the scope of this idea, some scholars have already begun to envision a worldwide database of local/indigenous environmental knowledge (Pennesi 2009 and __). Knowledge exchange among researchers, local populations, governments and other organizations is a critical component of democratization and for developing effective policies and adaptation strategies related to climate change.

Salick, Staver and Hart synthesize multiple studies which they undertook over many years with various interdisciplinary collaborators and using multiple ethnographic and participatory methods in China, Bhutan and Nepal. They describe the close connections between climate, people and vegetation in their work on ethnobotany of the Eastern Himalayan region. The input from numerous research partners enabled them to design a predictive model of how human and vegetation responses to climate change affect each other, asserting that the over-exploitation of medicinal plants, along with increased grazing and tourist activity at higher elevations, may strain the people, the animals and the pastures. Their prediction can inform policy in the Himalaya and provide a starting point for developing 
collaborative solutions. Additionally, their model can serve as an example for interdisciplinary research partnerships in other climate regions.

In Kenya, Roque de Pinho worked with Maasai pastoralists who took photos and videos documenting the impacts of severe drought on the land, the animals, and subsequently, the people. The participants then explained the photos and registered their complaints to government leaders and representatives of NGOs regarding fencing of private lands that hinder mobility of livestock and wildlife populations, and land use restrictions for conservation and urbanization. The herders used the photos as evidence of these and other problems and the research context provided an opportunity to present their concerns to people in power. These collaborations represent steps toward democratization as knowledge is jointly produced and shared for the benefit of those most acutely affected by climatic changes.

It is encouraging to see from the preceding chapters that scholars and their collaborators are exploring ways to share local/Indigenous knowledge of climate change and related effects. Some are also creating practical applications for their research. These collaborations succeed in considering social, economic and environmental variables that affect vulnerability, resilience and adaptation of different populations "to understand and develop approaches that are locally generated, owned and perpetuated" (Fiske et al. 2014:70). Looking ahead, Malsale and colleagues (2019) provide helpful guidance on best practices for collecting and documenting traditional climate knowledge, including developing legal protection for traditional knowledge and intellectual property, establishing local partnerships with institutions and communities, developing trust and involvement of the community in the project, and adhering to local protocols for sharing information. While these guidelines were developed by scholars working in the Pacific, their focus on respect and collaboration is relevant to many of the cases describing place-based knowledge in this book. The research presented here highlights the inadequacy and inappropriateness of simply extracting and decontextualizing information, as was done in the past. Creating relationships and partnerships with research participants is becoming the norm. Still, legal protection for intellectual property does not seem to figure in the projects discussed by the authors here. Working toward this would further the goal of decolonizing knowledge by legitimizing a plurality of epistemologies. Future collaborative work in these areas will have the highest potential to benefit communities if their participation and knowledge is truly supported in these ways.

\subsubsection{Activism and Social Transformation}

The final report of the American Anthropological Association's Global Climate Change Task Force (Fiske et al. 2014) highlights the value of community-centered approaches and interdisciplinary research in which anthropologists studying climate change are involved. The authors of the report argue that it is by working collaboratively with local peoples and with scholars who have different skills and perspectives that anthropologists can contribute most effectively to adaptation efforts at the local and regional level. Their starting assumption, and mine, is that anthropologists should be taking action. 
An illustrative example of this kind of politically engaged research in the current volume is the community-based project undertaken by Galvin and colleagues with Maasai pastoralists in Kenya. Together, they documented how changes in climate and environmental conditions (e.g. prolonged drought) led to compromised health of livestock as well as differences in animal and human behavior, which ultimately resulted in cultural change. The evident shift away from a traditional pastoral culture based on migration and structured social relations is explained not only in terms of access to available environmental resources, such as water and forage, but also in terms of economic activities and education. In light of this, the local groups proposed solutions that took into account both environmental factors and socio-political factors, suggesting the expansion of government offices, support for cross-border migration of people and animals, improved infrastructure, and the empowerment of women in spheres of education and finance. Here, we see how vulnerable communities can amplify their political voice in the pursuit of material improvements to their adaptive capacity by engaging in research partnerships with anthropologists and using the results to serve their own ends.

From the perspective of collaboration, it is heartening to learn from this group of researchers that local environmental knowledges and traditional or Indigenous knowledges are beginning to be taken seriously as complements to scientific research on climate and climate change. Several chapters (Katz et al.; Reyes-García et al.; Roque de Pinho; Seara et al.) illustrate how local knowledge can provide data at a scale and in regions where scientific data does not exist, adding further insight to other similar studies (Strauss 2003). Other chapters contribute to the growing literature documenting ethnometeorological and ecological knowledge to enhance basic understanding or inform predictions (Jiri et al. 2016; Magalhães 1963; Orlove et al. 2002; Speranza et al. 2010). Katz, Lammel and Bonnet describe micro-scale environmental knowledge about dew, lightning, winds and other observations that ribeirinhos use to predict weather and river levels in a floodplain of the Amazon River. Roque de Pinho provides a "schedule of rain" and explains how Maasai associate it with astronomical indicators of rain, in conjunction with their observations of wind direction, sunset color and the behavior of wild animals and birds. Dervieux and Belgherbi mention similar observational practices for generating predictions. The interactive web site CONECT-e, established by Reyes-García et al., contains a large collection of images and information about plants and the management of particular ecosystems. This kind of fine-grained data is valuable for others interested in these particular cultures and ecosystems, as well as for those making comparisons to other parts of the world. Acceptance of local knowledge as legitimate is a step toward decolonization, when "traditionally, science has been hostile to indigenous ways of knowing" (Smith 2012:265).

On the other hand, it appears that just when the value of such knowledge is finally being recognized outside of local communities, the number of practitioners is decreasing due to sociopolitical, religious and cultural shifts. In some cases, the practices and environmental indicators used to create indigenous knowledge are becoming less reliable (e.g. Katz et al.; Galvin et al.). In other cases, traditional knowledge is lost because elders are not passing it on to youth, who are occupied with other concerns or lack access to the necessary natural 
resources (e.g. Dervieux and Belgherbi; Roque de Pinho). Although not emphasized by this book's contributors, it is also important to recognize how ideological shifts stemming from colonial systems that work to devalue, delegitimize and even eliminate indigenous languages and cultural traditions have led to breaks in the intergenerational transmission of languages and traditional knowledge (Hill 2004). If people's languages and cultures are ridiculed, disallowed or ignored; if their work brings insufficient reward; if their bodies and personhood are abused; if their knowledge is discounted; then there arises an unwillingness to subject one's children and oneself to the same treatment by engaging in the same practices. Therefore, overcoming the subordinated group's belief in its own inferiority, or 'decolonizing the mind' (Fanon 1963; Ngũgĩ wa Thiong'o 1986), is necessary for the continued development of Indigenous environmental knowledge. Only when they have both symbolic and material value can Indigenous and other marginalized knowledges, cultures and communities flourish. Economic and cultural adaptations to changing climates are thus entangled with decolonization, language revitalization and cultural continuity. The societies described in this book have generally been adaptable and resilient when facing past environmental fluctuations and uncertainties, however, it is increasingly clear from these studies that changes are happening much more quickly and uncertainties are growing. Exacerbating the problem, political and economic factors create vulnerable communities with reduced adaptive capacity.

Anthropological research shows how crucial it is to illuminate the connections between a group's material conditions, its social position, its geopolitical location and how it is situated in specific ecologies.

If social transformation is the goal of anthropologists seeking to make a difference, it is at this point that it becomes important to engage in critical assessment of the situation. This book shows the effects of colonialism in places like Kenya, Zimbabwe and Brazil, and the socioeconomic disparities inherent in capitalism around the world, including in the global North. The contributors outline historical and political processes which have marginalized people who engage in land-based livelihoods, and especially indigenous peoples and their ways of knowing. Success in fishing, farming and herding are directly affected by fluctuations and changes in the climate and environment; yet so many of the populations who depend on these activities lack adequate access to resources that would enable effective adaptive responses, and they do not have the political power to improve their status. The objective then, cannot be simply to publish bits of indigenous or traditional knowledge which fill in gaps in the natural sciences or to secure a place for local collaborators to work alongside academic researchers. Understanding global change should inform work toward social change. As Linda Tuhiwai Smith (2012:266-267) reminds us, "Indigenous knowledge extends beyond the environment... it has values and principles about human behavior and ethics, about relationships, about wellness and leading a good life." In other words, Smith continues, our aim should not be to solve isolated problems, but to ensure the well-being of whole communities and to find ways to support them as they transform themselves. 
To do this, we need to move beyond doing research on local (subordinated, marginalized) people and how they adapt to the impacts of climate change, or research with those same subordinated groups as they create adaptive strategies appropriate to their contextual constraints. The next step requires us to turn around, step up and step aside. By 'turning around' I mean to turn our attention to investigating why and how dominant social groups continue to engage in environmentally destructive activities and to reproduce unjust policies that create the difficult conditions in which subordinated groups are living. To make a real difference, we must examine both how effective social change happens and what impedes it. Then, we can focus our energy on teaching our own privileged communities how to do things more equitably, more sustainably and more respectfully to reduce negative impacts on more vulnerable populations.

At the same time, we must 'step up' to help build the capacity of subordinated peoples to achieve their own goals. In other words, scholars, governments and others in powerful positions need to value Indigenous/local/traditional/rural people, not just their knowledge. Valuing the people can mean providing training, salaries and mentorship, not just a voice in the research process. One example is "Rising Voices: Collaborative Science with Indigenous Knowledge for Climate Solutions," a program funded by the National Center for Atmospheric Research (NCAR) and the University Corporation for Atmospheric Research (UCAR) in the U.S. To date, the program has held six workshops that "facilitate intercultural, relation-based approaches for understanding and adapting to extreme weather and climate events, climate variability and climate change" (UCAR 2019). Workshop participants include Indigenous leaders and professionals as well as scholars, educators, students and community leaders from around the world. They collaborate on "joint research aimed at developing optimal plans for community action towards sustainability" (UCAR 2019). Integral to this program's success are the ongoing mentorship in multiple domains, and the government funding provided to arrange and host the annual workshops, in addition to maintaining the network through regular communications, the web site, and the preparation of reports. The Rising Voices example shows that commitments of time, money and relationship building are part of the decolonization and democratization process. Anthropologists, and social scientists in general, can 'step up' to contribute their insights and their time, as well as their skills in grant-writing to increase competencies the in the communities where they work.

Valuing the people can also mean 'stepping aside' as principal investigators and assisting as funders or volunteers in Indigenous- or community-led projects. Indigenous Climate Action (https://www.indigenousclimateaction.com/) in Canada and the College of Menominee Nation Sustainable Development Institute (http://sustainabledevelopmentinstitute.org/) in the U.S. are excellent examples of this kind of initiative. There are surely others elsewhere in the world; we need to find them and support them. Valuing the people by stepping aside can also mean observing from a distance and learning in a way that does not burden them with teaching us. Our questions are not always the most important ones. 


\subsection{Implications and Future Directions}

Challenges remain in all four categories of anthropological research. In describing local knowledge and observations for outsiders, the specificity of local environments and cultures, the incommensurability of some forms of knowing, and the scalar mismatch of data types can make it difficult to generalize across contexts or to create models for integrating different kinds of environmental knowledge. If the aim is to disseminate this knowledge in a way that is useful to others, there is more work to be done on how to facilitate this kind of translation or exchange. But knowledge is not only produced for some collective benefit; it is also a form of resistance (Smith 2012:266). While anthropologists are getting better at supporting local people and collaborating with them, there is room to increase the degree to which research outputs and outcomes are actually beneficial to participants. One way to achieve this is to continue to find connections between experiences of climates changing and the social, cultural, political and economic factors that shape those experiences. A deeper understanding of context can open doors to more meaningful participation. The fourth category of decolonizing and democratizing research is still only emergent. Settler colonialism is ongoing. Social divisions within communities and political economic inequalities within nations are firmly entrenched, resisting efforts for systemic change. The purpose of anthropological research is to create new knowledge, gain deeper insights, and develop novel ways of thinking and doing things. Within the academy, researchers are obligated to publish in recognized scholarly venues, to teach and to serve the discipline in various ways, leaving limited time for engagement in communitybased activism. Moreover, as Andrew Walsh (2007:215) notes, "given the current state of the productivity regimes in which many of us work, the greatest deterrent to the development of new ways of doing anthropology is the possibility that some efforts simply will not count." It can be difficult to take a back-seat role in research design and implementation when we are expected to show leadership and demonstrate evidence of our individual productivity. And of course, not all anthropologists are convinced that we should be engaging politically through our research.

Nevertheless, this book provides reasons to be optimistic. Collaborative research and participatory methodologies such as those used here yield important results that can increase the relevance of findings to policy-makers and improve the effectiveness of adaptation strategies. For example, the work of Katz, Lammel and Bonnet paves the way for proposing better environmental management strategies that combine local micro-scale knowledge with scientific knowledge of rainfall and temperature fluctuations at a larger scale in the Amazon basin. The Maasai participants who worked alongside Roque de Pinho, Galvin and their colleagues are already in conversation with political leaders to advocate for improved policies and infrastructure, using their videos and photos to disseminate their environmental knowledge and observations of climate change. These projects build capacity among Maasai pastoralists as researchers and as contributors to political debates. Seara, Pollnac and Jakubowski show that policy and educational strategies around climate change adaptation are more likely to be accepted and implemented by Puerto Rican fishers if they incorporate local 
environmental knowledge and consider how factors like age, education, attitudes and experience influence perceptions. Burke, Welch-Devine, Steacy and Rzonca are facilitating "climate conversations" that engage diverse perspectives associated with residential characteristics and forms of land use to build solidarity among Appalachian community members and natural resource managers. These conversations can eventually lead participants to develop effective collective responses to climate change, despite deep political divisions. Sourdril et al. describe how community members can work together to care for public spaces despite their conflicting perspectives on environmental issues. The predictions of Salick, Staver and Hart for the Eastern Himalaya, while dire, have potential to compel decision-makers to move in new directions. Nearly every chapter offers suggestions or a path forward for how local environmental knowledge can inform management of resources and human adaptations to changing climates.

This book helps us see the importance of developing adaptive strategies for climate change that take into account sociocultural factors influencing relationships between people and their environment, as well as relationships among people that are mediated by the environment. After several decades of research around the globe, we are now entering a time when the 'locals' are becoming the researchers conducting studies in their own regions and communities, to evaluate adaptive strategies, programs and policies related to global changes. This research illustrates how people are already adapting to ongoing changes and how there is a history of adaptation and resilience in these communities. In future, the anthropologist's role may most appropriately be one of accompanying people as they face changes in progress, collaborating alongside them when asked, and using our power to contribute to social change where we live.

\section{References}

Ayers, Jessica and Tim Forsyth (2009) Community-Based Adaptation to Climate Change. Environment: Science and Policy for Sustainable Development 51(4): 22-31.

Baer, Hans and Merrill Singer (eds.) (2018) The Anthropology of Climate Change: An Integrated Critical Perspective, $2^{\text {nd }}$ edition. New York: Routledge.

Barnes, Jessica and Michael Dove (eds.) (2015) Climate Cultures: Anthropological Perspectives on Climate Change. New Haven: Yale Uni Press.

Barnes, Jessica, Dove, M., Lahsen, M., Mathews, A., McElwee, P., Mclntosh, R., Moore, F., O'Reilly, J., Orlove, B., Puri, R., Weiss, H., and Yager, K. (2013) Contribution of Anthropology to the Study of Climate Change. Nature Climate Change 3: 541-544. doi:10.1038/nclimate1775

Blaikie, P., Cannon, T., Davis, I., \& Wisner, B. (1994). At Risk: Natural Hazards, People's Vulnerability and Disasters. New York: Routledge. 
Casagrande, David, Hope, D., Farley-Metzger, E., Cook, W., Yabiku, S., and Redman, C. (2007) Problem and Opportunity: Integrating Anthropology, Ecology, and Policy through Adaptive Experimentation in the Urban U.S. Southwest. Human Organization 66(2): 125-139.

Crate, Susan and Mark Nuttall (eds.) (2009) Anthropology and Climate Change: From Encounters to Actions. New York: Routledge.

Crate, Susan and Mark Nuttall (eds.) (2016) Anthropology and Climate Change: From Actions to Transformations, $2^{\text {nd }}$ edition. New York: Routledge.

Dove, Michael (ed.) (2014) The Anthropology of Climate Change: An Historical Reader. Malden, MA: Wiley Blackwell.

Dove, Michael and Carol Carpenter (eds.) (2008) Environmental Anthropology: A Historical Reader. Malden, MA: Blackwell Publishing.

Fanon, F. (1963). The Wretched of the Earth. New York: Grove Press.

Fiske, S.J., Crate, S.A., Crumley, C.L., Galvin, K., Lazrus, H., Lucero, L. Oliver-Smith, A., Orlove, B., Strauss, S., and Wilk, R. (2014) Changing the Atmosphere: Anthropology and Climate Change. Final report of the AAA Global Climate Change Task Force, 137 pp. December 2014. Arlington, VA: American Anthropological Association.

Hill, J. (2004). What is Lost When Names are Forgotten? In G. Sanga \& G. Ortalli (Eds.), Nature Knowledge: New York: Berghahn Press.

IPCC (Intergovernmental Panel on Climate Change) (2013). Summary for Policymakers. In Climate Change 2013: The Physical Science Basis. Contribution of Working Group I to the Fifth Assessment Report of the Intergovernmental Panel on Climate Change [Stocker, T.F., D. Qin, G.-K. Plattner, M. Tignor, S.K. Allen, J. Boschung, A. Nauels, Y. Xia, V. Bex and P.M. Midgley (eds.)]. New York: Cambridge University Press.

Jankovic, Vladimir and Christina Barboza (eds.) (2009) Weather, Local Knowledge and Everyday Life: Issues in Integrated Climate Studies. Rio de Janeiro, MAST.

Jiri, O., Mafongoya, P., Mubaya, C., \& Mafongoya, O. (2016). Seasonal Climate Prediction and Adaptation Using Indigenous Knowledge Systems in Agriculture Systems in Southern Africa: A Review. Journal of Agricultural Science, 8(5), 156-172.

Lazrus, Heather (2012) Sea Change: Island Communities and Climate Change. Annual Review of Anthropology 41:285-301.

Magalhães, J. (1963). Previsões Folclóricas das Sêcas e dos Invernos no Nordeste Brasileiro. Fortaleza: Imprensa Universitária do Ceará.

Malsale, Philip, Sanau N., Tofaeono T.I., Kavisi Z., Willy A., Mitiepo R., Lui S., Chambers L.E., and Plotz R.D. (2019) Protocols and Partnerships for Engaging Pacific Island Communities in the 
Collection and Use of Traditional Climate Knowledge. Bulletin of the American Meteorological Society 99:2471-2489. https://journals.ametsoc.org/doi/10.1175/BAMS-D-17-0163.1

Mohanty, Chandra Talpade (2003) Feminism without Borders: Decolonizing Theory, Practicing Solidarity. Duke University Press.

Moran, E. F. (2008). Human Adaptability: An Introduction to Ecological Anthropology (3 ${ }^{\text {rd }}$ ed.). Boulder: Westview Press.

Ngũgĩ wa Thiong'o. (1986). Decolonising the Mind: The Politics of Language in African Literature. Portsmouth, N.H.: Heinemann.

Orlove, B., Chiang, J., \& Cane, M. (2002). Ethnoclimatology in the Andes: A Cross-disciplinary Study Uncovers a Scientific Basis for the Scheme Andean Potato Farmers Traditionally Use to Predict the Coming Rains. American Scientist, 90(5), 428-435.

Pennesi, K. (2009). Creating an Online Archive of Traditional Weather Prediction Indicators: Notes from a roundtable discussion. In V. Jankovic \& C. Barboza (Eds.), Weather, Local Knowledge and Everyday Life: Issues in Integrated Climate Studies (pp. 297-304). Rio de Janeiro: MAST.

Pennesi, K. (2011). Making Forecasts Meaningful: Explanations of Problematic Predictions in Northeast Brazil. Weather, Climate and Society, 3(2), 90-105.

Pennesi, K. (2013). Predictions as Lies in Ceará, Brazil: The Intersection of Two Cultural Models. Anthropological Quarterly, 86(3), 759-790.

Pennesi, K. (2015). Constructing 'Farmer' and 'State' Identities in Moral Discourses about Semisubsistence Agriculture in North-east Brazil. Journal of Latin American Studies, 47(4), 781-809.

Pennesi, K., \& Souza, C. R. B. d. (2012). O Encontro Anual dos Profetas da Chuva em Quixadá, Ceará: A Circulação de Discursos na Invenção de uma Tradição (The Annual Meeting of Rain Prophets in Quixadá, Ceará: The Circulation of Discourses in the Invention of Tradition). Horizontes Antropológicos, 38, 159-186. DOI http://dx.doi.org/10.1590/S0104$\underline{71832012000200007}$

Pokrant, Bob and Laura Stocker (2011) Anthropology, Climate Change and Coastal Planning. In Environmental Anthropology Today. H. Kopnina and E. Shoreman-Ouimet (eds.). New York: Routledge. Pp. 179-194.

Reuter, Thomas (2015) Averting a Global Environmental Collapse: The Role of Anthropology and Local Knowledge. Newcastle upon Tyne: Cambridge Scholars Publishing.

Ribot, J., Najam, A., \& Watson, G. (1996). Climate Variation, Vulnerability and Sustainable Development in the Semi-arid Tropics. In J. Ribot, A. Magalhães, \& S. Panagides (Eds.), Climate 
Variability, Climate Change and Social Vulnerability in the Semi-arid Tropics (pp. 13-51). Cambridge: Cambridge University Press.

Smith, Linda Tuhiwai (2012) Decolonizing Methodologies: Research and Indigenous Peoples, $2^{\text {nd }}$ ed. New York: Palgrave Macmillan.

Speranza, C. I., Kiteme, B., Ambenje, P., Wiesmann, U., \& Makali, S. (2010). Indigenous Knowledge Related to Climate Variability and Change: Insights from Droughts in Semi-arid Areas of Former Makueni District, Kenya. Climatic Change, 2010(100), 295-315.

Strauss, S. (2003). Weather Wise: Speaking Folklore to Science in Leukerbad. In S. Strauss \& B. Orlove (Eds.), Weather, Climate, Culture (pp. 39-60). New York: Berg.

Strauss, Sarah and Benjamin Orlove (eds.) (2003) Weather, Climate, Culture. New York: Berg.

Taddei, R. (2006). Oráculos da chuva em tempos modernos: Mídia, desenvolvimento econômico e as transformações na identidade social dos profetas do sertão (Modern Day Rain Oracles: Media, Economic Development and Transformations of the Social Identity of Rain Prophets). In K. P. H. Martins (Ed.), Profetas da Chuva (pp. 161-170). Fortaleza: Tempo d'Imagem.

Taddei, R. (2012). Social Participation and the Politics of Climate in Northeast Brazil. In A. Latta \& H. Wittman (Eds.), Environment and Citizenship in Latin America: Natures, Subjects and Struggles (pp. 77-93). New York: Berghahn Books.

Tuck, E. \& K. W. Yang (2012). Decolonization Is Not a Metaphor. Decolonization: Indigeneity, Education and Society, 1(1), 1-40.

UCAR (University Corporation for Atmospheric Research) (2019). Rising Voices.

https://risingvoices.ucar.edu/.

Walsh, A. (2007). Ethnographic Alchemy: Perspectives on Anthropological Work from Northern Madagascar. In Les Field and Richard G. Fox, (Eds.), Anthropology Put to Work (pp. 201-216). Oxford: Berg Publishers. 